\title{
Gastroscopy and gastric photography with the Olympus GTF-A
}

\author{
R. COCKEL AND C. F. HAWKINS \\ From Queen Elizabeth Hospital, Birmingham
}

SUMMARY One hundred patients were examined with the Olympus GTF-A fibregastroscope and gastrocamera. The entire stomach was seen in most cases; the technique permitting this is described in detail. The examination was most rewarding in patients with gastric haemorrhage and when radiology was equivocal. Advantages and disadvantages of the instrument are discussed.

Gastroscopy, once referred to as a 'narrow peeping speciality' (Rogers, 1937), has been transformed by the development of new instruments (Morrissey, Tanaka, and Thorsen, 1967). Now, instead of requiring long experience and persistent practice, gastroscopy can be performed with little difficulty. A major advance was the application of fibreoptics to gastroscopy by Hirschowitz and his colleagues (Hirschowitz, Curtiss, Peters, and Pollard, 1958; Hirschowitz, 1961 ; Hirschowitz, Balint, and Fulton, 1962), for the flexible fibrescope reduces the patient's discomfort and lessens the risk of oesophageal perforation. The Japanese optical industry improved the fibrescope and developed the intragastric camera; this miniature camera can be used alone (Hadley, 1965) or combined with the fibrescope (Gibbs, 1967).

Today, the gastroscopist is faced with a bewildering number of expensive instruments; one may be suitable for examining the proximal stomach, whereas another is preferable for the distal part or may include facilities for gastric cytology and biopsy (Williams, Truelove, Gear, Massarella, and Fitzgerald, 1968). The Olympus GTF-A fibrescope and gastrocamera (Fig. 1) allows the entire stomach to be seen and photographed. We record our experiences after examining 100 patients.

\section{Description of Instrument}

The Olympus GTF-A is $10.2 \mathrm{~mm}$ in diameter in the flexible part and $12.7 \mathrm{~mm}$ in diameter at the rigid tip of $6.5 \mathrm{~cm}$ where the camera is enclosed (Figure 2). It is better than the Hirschowitz fibrescope because of the clearer view due to the quality of fibre bundles, increased magnification, and a wider angle of viewing which makes orientation easier. The intragastric camera has a photographing angle of $80^{\circ}$, including the whole of the area seen through the fibre bundle, so avoiding parallax. The instrument also has a remote control mechanism which permits the distal $8 \mathrm{~cm}$ to be moved forwards and backwards through an angle of $140^{\circ}$; the upper part of the stomach, cardia, and fundus, can then be seen.

\section{Technique of Intubation}

Careful explanation and reassurance are essential beforehand, for swallowing a tube is largely a psychological problem. The examination is carried out in a side-room of the ward. The patient is in bed lying with his head at the foot end and premedicated with an injection of papaveretum 10 to $20 \mathrm{mg}$ and hyoscine $0.4 \mathrm{mg}$; 


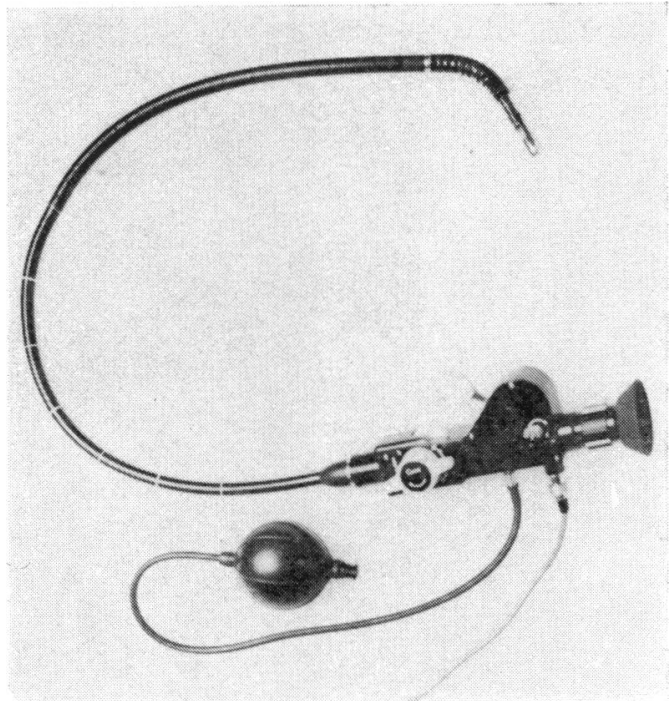

Fig. 1 The fibrescope and gastrocamera (Olympus GTF-A).

alternatively, diazepam $10 \mathrm{mg}$ can be given intravenously. The mouth and pharynx are sprayed with $4 \%$ lignocaine from a pressurized bottle. The oropharynx is then palpated to test for anaesthesia.

We photograph each patient's name and hospital number directly from the case notes at the start while testing the bulb, then intragastric photographs can be identified if the same film is used for several cases. With the patient lying on the left side with the head flexed so that he can swallow easily, the lubricated fibrescope is guided by a finger to the laryngopharynx. A swallow is essential, otherwise the tip may lodge in a piriform fossa, especially in the elderly when heavily sedated. If this happens, it must be withdrawn for further swallowing only lifts the instrument and causes discomfort. Passing it into the upper oesophagus is the most difficult part of the procedure; patience is needed, for pushing without a swallow usually fails. After the cricopharyngeal sphincter has been passed, it goes freely down the oesophagus, aided if necessary by slipping the flexible tube over a lubricated swab. Any slight resistance at the cardia can be overcome by gently insufflating air. When the tip has passed the cardia, the stomach is inflated. Vision should then be clear unless the lens is lying in gastric juice or against the mucosa, when moving it permits a view. Sometimes mucus causes blurring; we then withdraw the tip of the

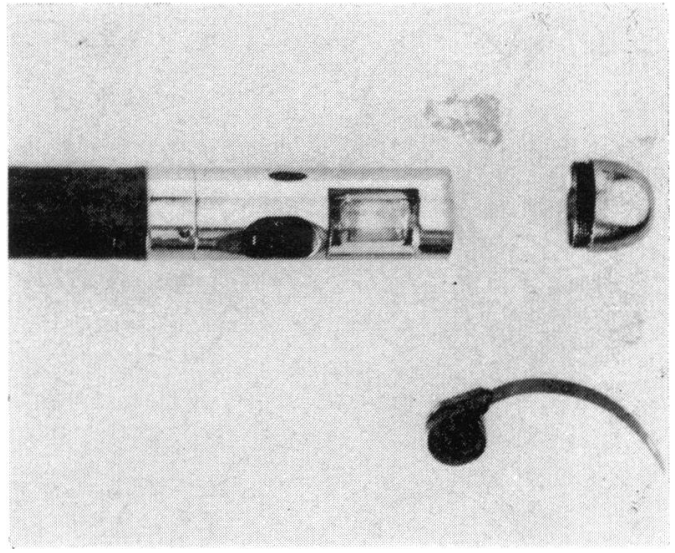

Fig. 2 Rigid tip of GTF-A and film cassette.

fibrescope into the lower oesophagus and use the sphincter to wipe the lens.

Landmarks are easily recognized. With the patient in the left lateral position, the angulus and antrum are seen and the pylorus is examined. If the pylorus cannot be seen, we bend the tip towards the pylorus, push it blindly into the antrum and bend it back again (Figure 3). In a hypermotile stomach, the pylorus may be obscured by peristaltic waves; these can be quietened by giving $10 \mathrm{mg}$ propantheline intravenously when further inflation will reveal the antrum and pylorus. The lesser curve, the anterior and posterior walls, and the fundus of the stomach are examined systematically by gradually withdrawing and rotating the instrument. The patient can move into any position that improves the view-on the left or right side, or supine; this may be necessary when gastric juice is copious Preliminary gastric aspiration is indicated when gastric stasis is shown radiographically.

The best way to see the fundus and cardia is by the U-turn manoeuvre. The patient lies supine and the tip of the fibrescope is rotated so that it lies free in the body of the stomach with the large folds of the greater curve in view; the tip is angulated fully to the left and the tube slowly though firmly advanced to make it curl upon itself (Figure 4). The patient is warned that he may feel some slight discomfort. After a time, and perhaps only when the fibrescope is 

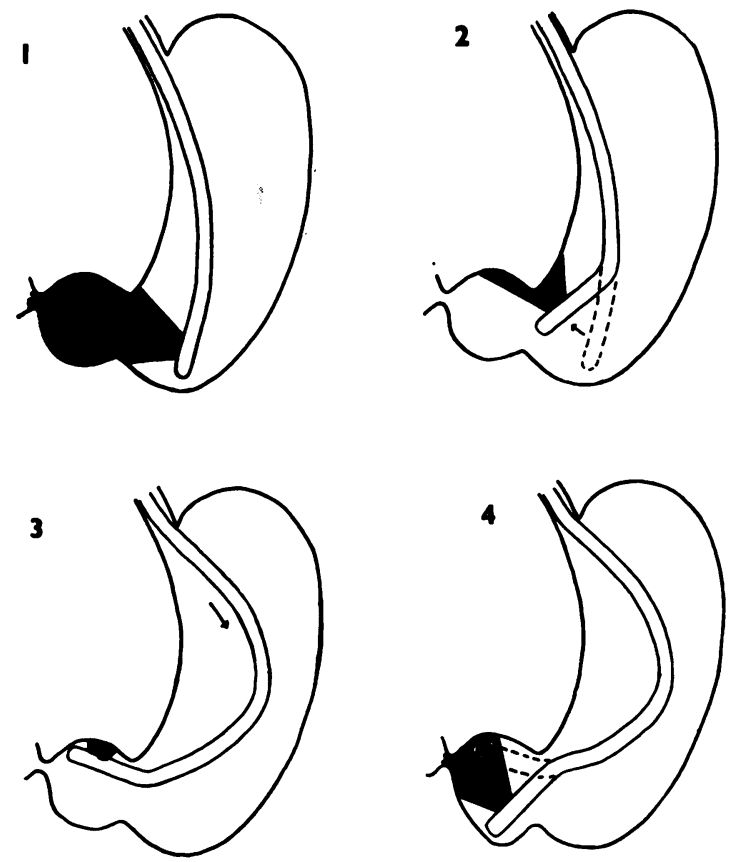

Fig. 3 Method of viewing the pylorus.

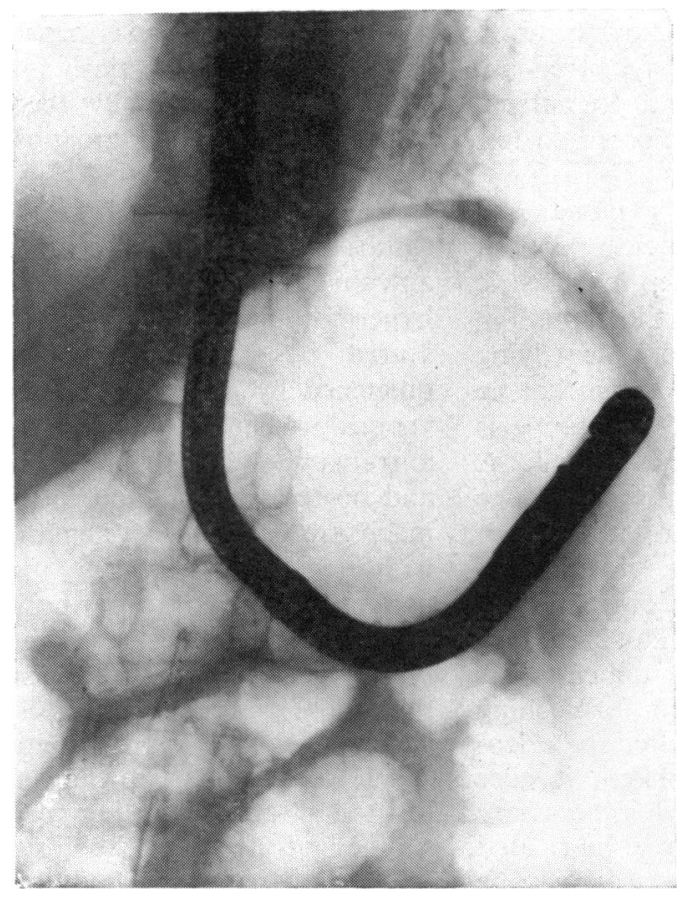

Fig. 4 Radiograph showing U-turn to view the cardia and lesser curve.

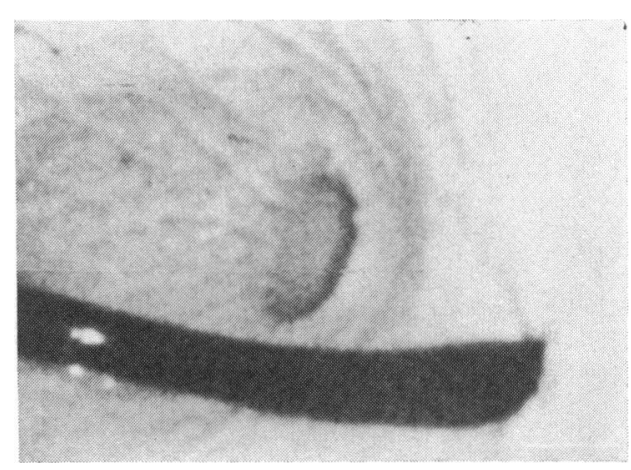

Fig. 5 Photograph taken by gastrocamera showing proximal part of instrument passing through the cardia and body of stomach.

passed to its hilt, the operator sees the tube as it enters the stomach (Fig. 5) and a panoramic view of the lesser curve is obtained by further manipulation.

Fluoroscopy has been recommended to aid orientation. Initially we watched routinely on the image intensifier as the fibrescope was swallowed and when it explored the stomach. This was soon abandoned as unnecessary except, on rare occasions, when the instrument does not pass easily down the oesophagus. It is simpler and less worrying for a patient to be examined in a quiet side-room off the ward. The position of the light and flash through the abdominal wall were also observed at the start. These methods, though helpful when the gastrocamera alone is used (Hadley, 1965; Scarrow, 1967), are unnecessary with the combined fibrescope and gastrocamera.

\section{Indications for Use}

'Blind areas' in the stomach virtually no longer exist, but indications are similar to those accepted for other methods of gastroscopy: (1) To exclude gastric ulcer when the history is suggestive although a barium meal is normal. (2) To distinguish between gastric ulcer and a fleck of barium lying in a gastric fold. (3) For immediate diag- 


\begin{tabular}{|c|c|c|c|c|c|c|c|c|}
\hline \multirow[t]{2}{*}{ Reason for Examination } & \multirow{2}{*}{$\begin{array}{l}\text { No. of } \\
\text { Cases }\end{array}$} & \multicolumn{7}{|c|}{ Results of Examination } \\
\hline & & Normal & $\begin{array}{l}\text { Benign } \\
\text { Ulcer }\end{array}$ & Carcinoma & $\begin{array}{l}\text { Benign } \\
\text { Tumour }\end{array}$ & 'Gastritis' & Other & $\begin{array}{l}\text { Change in } \\
\text { Clinical } \\
\text { Management }\end{array}$ \\
\hline $\begin{array}{l}\text { Benign gastric ulcer } \\
\text { Gastric carcinoma } \\
\text { Benign tumour } \\
\text { Haemorrhage } \\
X \text {-ray-negative dyspepsia } \\
\text { Postoperative dyspepsia } \\
\text { Doubtful radiographic appearances } \\
\text { Review } \\
\text { Other }\left\{\begin{array}{l}2 \text { pyloric stenosis } \\
2 \text { lesser curve } \\
\text { diverticula } \\
1 \text { hiatal hernia }\end{array}\right.\end{array}$ & $\begin{array}{r}13 \\
6 \\
3 \\
12 \\
33 \\
14 \\
11 \\
6\end{array}$ & $\begin{array}{r}3 \\
1 \\
0 \\
3 \\
20 \\
5 \\
1 \\
0\end{array}$ & $\begin{array}{l}8 \\
1 \\
0 \\
4 \\
2 \\
2 \\
3 \\
3\end{array}$ & $\begin{array}{l}1^{1} \\
1 \\
1 \\
0 \\
0 \\
0 \\
2 \\
0\end{array}$ & $\begin{array}{c}0 \\
0 \\
1,1^{1} \\
1 \\
1 \\
1 \\
0 \\
0\end{array}$ & $\begin{array}{l}1 \\
1 \\
0 \\
4 \\
7 \\
3 \\
4 \\
3\end{array}$ & $\begin{array}{l}\mathbf{0} \\
2 \\
0 \\
0 \\
3 \\
3 \\
1 \\
0\end{array}$ & $\begin{array}{l}2 \\
5 \\
1 \\
4 \\
3 \\
3 \\
7 \\
0\end{array}$ \\
\hline
\end{tabular}

Table Results in 100 cases examined by the Olympus GTF-A

${ }^{1}$ Misdiagnosed by gastroscopy

nosis of gastric erosions causing haemorrhage, as these are not seen radiographically. (4) To search for carcinoma. (5) To exclude stomal ulcer as the cause of dyspepsia after partial gastrectomy. (6) To elucidate uncertain radiographic appearances, particularly in the prepyloric area.

\section{Patients}

One hundred inpatients have been examined and the only complication has been slight discomfort in the throat lasting a few hours afterwards. Some were examined for more than one reason, for example, post operative dyspepsia and bleeding, so the numbers of provisional diagnoses (Table) add up to more than one hundred.

\section{Results}

Thirteen patients with a provisional diagnosis of simple gastric ulcer were examined and this diagnosis was confirmed in eight. In one, a benign ulcer was wrongly considered malignant; this did not, however, affect treatment as operation was advised anyway. Three suspected ulcers were not seen; one may have healed before gastroscopy and a suspicious niche in two patients was due to barium lodged between prominent mucosal folds and not to an ulcer. In the remaining patient there was no ulcer but erosive gastritis was found.

Gastric carcinoma was confirmed in one patient and disproved in five: one was normal, one had a simple ulcer, one showed hour-glass deformity due to a healed chronic ulcer, one had giant rugal hypertrophy, and the other hypertrophic gastritis. Three patients with suspected benign tumour were examined: this was confirmed in one but in another the tumour was shown to be a carcinoma; in the third, a smooth filling defect in the body of the stomach was thought to be benign at gastroscopy but operation proved it to be a secondary carcinoma in a paraaortic lymph node which had invaded the stomach; as the mucosa was intact there was nothing to suggest the true diagnosis.

A source for haemorrhage was found in nine of 12 patients (Table); in the three in whom examination was normal, one was unexplained, one had probably bled from diverticulitis of the colon, and the other was a patient with a Polya partial gastrectomy who had bled two weeks previously and may have had erosions which had healed.

Few new diagnoses were made in cases of $x$-ray-negative dyspepsia. Two unrecognized simple ulcers were discovered but no carcinomata. Several examples of chronic gastritis, one of giant rugal hypertrophy, and one of transpyloric antral mucosal prolapse were seen though the relationship to symptoms was uncertain. Gastric telangiectasis was confirmed in a patient with the Osler-Weber-Rendu syndrome, but no ulcer was found. Postoperative dyspepsia was seen to be due to a recurrent ulcer in two patients after vagotomy and pyloroplasty. In three after partial gastrectomy, exposed sutures (Palmer, 1949) were present in two, and, when the suture material was removed in one of these, symptoms disappeared; in the third, a deep sinus proximal to the suture line was seen. The review examina- 
tions showed the same appearances as on the first occasion except for simple ulcers which were healing or healed.

Doubtful radiographic appearances were satisfactorily explained in all 11 patients. Prepyloric deformity was due to benign ulcer in two, carcinoma in two, antral gastritis in four, and to disturbed motility in one; in this last patient the antrum showed increased peristalsis and, when this was abolished with propantheline, the mucosa was seen to be normal. Two high lesser curve gastric diverticula were confirmed; one was associated with a benign ulcer near the angulus which had been missed in the radiograph. Pyloric stenosis was shown to be malignant in one, while in another the presumed diagnosis of fibrosis from duodenal ulcer was supported. A single case of large rolling hiatal hernia was examined, and the mucosa in the sac showed areas of gastric erosion. Generally, however, we have not obtained views of small herniae. Altogether, 28 new diagnoses, either the discovery of an unrecognized lesion or disproof of a suspected abnormality, were made in 100 examinations.

There were seven failures, two from inexperience at the beginning and one patient was uncooperative. In another, uncontrolled retching occurred when the fibrescope was in the stomach; we think, in retrospect, that intravenous diazepam, $10 \mathrm{mg}$, in addition to the premedication would have overcome this. The instrument could not be passed into the stomach in two patients; one was found to have carcinoma of the cardia and the other a recurrence of carcinoma after proximal gastric resection. The remaining failure was in a patient with haematemesis. Although a large-bore tube was used to remove clot from the stomach, no view was obtained.

\section{Discussion}

The Olympus GTF-A is a relatively simple instrument to use. It was well tolerated by most patients and those questioned preferred this examination to swallowing a plastic nasogastric tube, probably because of the premedication. The adjustable end allows the pylorus to be seen in most patients. The U-turn manoeuvre permits the cardia to be examined and a fine view of the lesser curve is often obtained at the same time. Its clinical value exceeded our expectations and altered the clinical management of $20 \%$ of our patients. Fibregastroscopy does not replace other diagnostic procedures but, used in a complementary manner, it increases diagnostic accuracy.

Although an ideal gastroscope has yet to be produced, we feel that being able to examine the entire stomach is more valuable then the incomplete view obtained with the Olympus GFB (Williams et al, 1968) which also has facilities for biopsy and cytology. If a lesion shows features suggestive of malignancy, exfoliative cytology may be performed with a separate tube at the same time as fibregastroscopy (Kidokoro, 1966; Blendis, Beilby, Wilson, Cole, and Hadley, 1967). The tube for gastric lavage can be passed alongside the fibrescope, and some measure of guidance is possible so that a jet of saline can be directed at the lesion. When neoplasm is suspected and cytology or even biopsy is negative, laparotomy would in any case be recommended. In the experience of Williams et al (1968) all ulcers subsequently shown to be malignant had atypical features at gastroscopy, although the radiographic diagnosis was simple ulcer. It thus seems unlikely that an experienced observer would often misdiagnose carcinoma as a benign ulcer. However, no technique is infallible, as is shown by the occasional discovery of microscopic carcinoma in stomachs resected for apparently typical benign gastric ulcer.

Those investigated for gastric haemorrhage and doubtful radiographic appearances were the most rewarding in permitting accurate diagnosis. However, in patients with $x$-ray-negative dyspepsia and postoperative dyspepsia, some diagnoses were made which otherwise would have been overlooked. Review examinations with the fibregastroscope were more satisfactory than by barium meal in assessing healing of ulcers, as the mucosal covering of the crater could be easily seen and filling in of a crater by malignant tissue is excluded. Patients with carcinoma seldom required gastroscopy as diagnosis was obvious as seen by barium meal but fibregastroscopy prevented unnecessary laparotomy where the radiologist had raised doubts about possible malignancy, as may happen with large, irregular gastric folds. Direct vision of suspicious areas has been more satisfactory than the experience of Blendis et al (1967) using the blind gastrocamera without the fibrescope. Also, unsatisfactory examinations after the tube has been introduced into the stomach have been rare.

Intragastric photographs are useful as an objective record of examinations, and for comparison and teaching, though in no case have we made observations from film strips which were overlooked during the examination. Photography under direct vision is more economical of films than blind photography, despite the fact that alternate frames are wasted during viewing as the camera has no shutter. Up to four examinations have been recorded with the patients' names on a single film strip of 32 exposures. Film strips can be studied by four or five people using the Olympus gastroprojector and, for larger meetings, pictures can be projected on to any screen at 10 to $15 \mathrm{ft}$, or $35 \mathrm{~mm}$ slides can be made from the photomicrographs.

There are disadvantages. Great care is needed to keep the air tube patent and it must be blown through fastidiously immediately after each 
examination. Otherwise, if a trace of mucus becomes inspissated in the orifice, there is no means of clearing it and the instrument has to be sent to the makers. In addition to air inflation, we squirt a jet of water at the distal opening to keep it clean; no liquid, however, must be squirted through the air tube itself. Another snag is that the end must not be bent until four photographs have been taken or the film leader may be bent. Problems encountered in taking good colour photographs have been overexposure and scratches on the film. Scratches are caused by damage to the emulsion as the film passes through the opening of the cassette and through the channel within the fibrescope or connecting tubes. Pictures may overlap, particularly when turning on the film with the end of the fibrescope bent.

The Olympus GTF-A fibregastroscope and gastrocamera is a good general purpose endoscope, with advantages over other available instruments. If possession of more than one piece of equipment is not financially possible, this would seem to be the instrument of choice today.

The GTF-A fibregastroscope and gastrocamera was generously donated by Merck, Sharp and Dohme Limited.
References

Blendis, L. M., Beilby, J. O. W., Wilson, J. P., Cole, M. J., and Hadley, G. D. (1967). Carcinoma of the stomach; evaluation of individual and combined diagnostic accuracy of radiology, cytology and gastrophotography. Brit. med. J., 1, 656-659.

Gibbs, D. D. (1967). Gastric endoscopy. Hosp. Med., 2, 154-158. Hadley, G. D. (1965). The gastrocamera. Brit. med. J., 2, 12091212.

Hirschowitz, B. I., Curtiss, L. E., Peters, C. W., and Pollard, H. M. (1958). Demonstration of a new gastroscope, the 'Fiberscope'. Gastroenterology, 35, 50-53.

Hirschowitz, B. I. (1961). Endoscopic examination of the stomach and duodenal cap with the fiberscope. Lancet, 1, 1074-1078.

Hirschowitz, B. I., Balint, J. A., and Fulton, W. F. (1962). Gastroduodenal endoscopy with the fiberscope-an analysis of 500 examinations. Surg. Clin. N. Amer., 42, 10811090.

Kidokoro, T. (1966). Direct vision cytology and biopsy of the stomach. Gastroent. endosc., 8, 1-42.

Morrissey, J. F., Tanaka, Y., and Thorsen, W. B. (1967). Gastroscopy. A review of the English and Japar se literature. Gastroenterology, 53, 456-76.

Palmer, E. D. (1949). Stomach Disease as Diagnosed by Gastroscopy, p. 154. H. Kimpton, London.

Rogers, H. W. (1937). In Preface to the Textbook of Gastroscopy by Norbert Henning. Oxford University Press, London: Humphrey Milford.

Scarrow, G. D. (1967). Radiology of the stomach and the gastric camera. Brit. J. Radiol., 40, 23-29.

Williams D. G., Truelove, S. C., Gear, M. W. L., Massarella. G. R., and Fitzgerald, N. W. (1968). Gastroscopy with biopsy and cytological sampling under direct vision. Brit. med. J., 1, 535-539. 